\title{
Carcinoma de células escamosas na base do chifre com metástase pulmonar em um bovino: relato de caso
}

\author{
Squamous cell carcinoma at horn base with pulmonar \\ metastasis in a bovine: a case report
}

\author{
Tuanna Ranyelli Ramalho Fernandes ${ }^{1 *}$, Anderson Luiz de Araújo², Fernando Passon Casagrande³, \\ Vitor Santiago de Carvalho ${ }^{4}$, Anna Fernanda Machado Sales da Cruz Ferreira ${ }^{4}$, Karina Medici Madureira ${ }^{5}$, \\ André Marandola dos Santos ${ }^{6}$, Vivian de Assunção Nogueira ${ }^{7}$ \& Tiago da Cunha Peixoto ${ }^{5}$ \\ 'Discente do Curso de Medicina Veterinária. Escola de Medicina Veterinária e Zootecnia, Universidade Federal da Bahia - UFBA, \\ Salvador, BA, Brasil \\ 2Médico veterinário, Técnico administrativo em educação. Hospital de Medicina Veterinária, Universidade Federal da Bahia - \\ UFBA, Salvador, BA, Brasil \\ ${ }^{3}$ Médico veterinário, Professor do Curso de Medicina Veterinária. Universidade Federal do Pampa - UNIPAMPA, Uruguaiana, \\ RS, Brasil \\ ${ }^{4}$ Médicos veterinários. Centro de Desenvolvimento da Pecuária, Universidade Federal da Bahia - UFBA, Santo Amaro, BA, Brasil \\ ${ }^{5}$ Médicos veterinários. Departamento de Anatomia, Patologia e Clínicas Veterinárias, Escola de Medicina Veterinária e Zootecnia \\ - UFBA, Salvador, BA, Brasil \\ ${ }^{6}$ Médico veterináro. Programa de Pós-graduação em Medicina Veterinária, Instituto de Veterinária - IV, Universidade Federal \\ Rural do Rio de Janeiro - UFRRJ, Seropédica, RJ, Brasil \\ `Médica veterinária. Departamento de Epidemiologia e Saúde Pública, Instituto de Veterinária - IV. Universidade Federal Rural \\ do Rio de Janeiro - UFRRJ, Seropédica, RJ, Brasil
}

\section{Resumo}

Descreve-se um caso de carcinoma de células escamosas na base do chifre com metástase pulmonar em um bovino prenhe. Em novembro de 2015, uma vaca Gir com nove anos de idade foi atendida no Centro de Desenvolvimento da Pecuária (CDP) da UFBA. Segundo o proprietário, o animal apresentou lesão traumática na base do chifre esquerdo devido ao uso de corda, a qual não respondeu ao tratamento e resultou em rotação do chifre. Ao exame físico observaram-se grande massa tumoral (16x17x8cm), irregular, fétida, de consistência esponjosa e aspecto de couve-flor, pruriginosa e de fácil sangramento, localizada na pele crânioventral à base do chifre e orelha esquerda que se infiltrava profundamente para o interior do chifre esquerdo. Foram realizados exames complementares: hemograma, exame radiográfico e a biopsia da massa tumoral. O hemograma revelou anemia severa, hipoproteinemia e leucocitose. A radiografia evidenciou invasão dos terços proximal e médio do chifre esquerdo pela massa tumoral e proeminências que circundavam os ossos da cabeça. A avaliação histopatológica evidenciou que a massa era constituída por proliferação de células epiteliais neoplásicas, moderadamente diferenciadas com núcleos arredondados a ovoides, arranjados em cordões irregulares e ninhos sólidos entremeados por escasso estroma fibroso; notou-se caráter infiltrativo manifesto. O diagnóstico carcinoma de células escamosas (CCE) da base do chifre foi estabelecido com base no histórico, sinais clínicos, epidemiologia e exame histopatológico. Devido à gestação avançada e condição clínica precária, o tratamento de suporte foi indicado para estabilização do paciente até o parto, para somente então ser realizado o tratamento cirúrgico com ressecção da massa tumoral associado a descorna. Contudo, após o parto, a vaca apresentou piora significativa do quadro clínico, com decúbito persistente, inapetência, anemia severa, fraqueza generalizada, sem resposta aos tratamentos realizados. Devido ao prognóstico desfavorável o proprietário optou pela eutanásia. Após a morte o animal foi necropsiado. Durante a necropsia verificou-se que a massa tumoral infiltrava as porções proximal e média internas do corno esquerdo, bem como todo o seio frontal esquerdo associada a intenso exsudato purulento e detritos celulares. Adicionalmente observaram-se nos lobos caudais dos pulmões múltiplos nódulos esbranquiçados com até 3,0cm de diâmetro com características macroscópicas semelhantes ao tumor da base de chifre. A avaliação microscópica revelou tratar-se de metástase do CCE da base do chifre.

Palavras-chave: neoplasia, bovino, chifre, metástase.

\section{Abstract}

This paper describes a squamous cell carcinoma in the horn base with lung metastasis in pregnant cattle. A cow, female, Gir nine year old was treated at the Livestock Development Centre / Ruminant clinic on 2015. In the anamnesis was reported by the owner, the animal developed a wound rope at the base of
Como citar: Fernandes, T. R. R., Araújo, A. L., Casagrande, F.P., Carvalho, V.S., Ferreira, A. F.M. S.C., Madureira, K. M., Santos, A. M., Nogueira, V. A. \& Peixoto, T. C. (2017). Carcinoma de células escamosas na base do chifre com metástase pulmonar em um bovino: relato de caso. Brazilian Journal of Veterinary Medicine, 39(3), 208-214. doi: 10.29374/2527-2179.bjvm013316

Fonte de financiamento: Nenhuma.

Conflito de interesses: Os autores declaram não haver conflito de interesses que precisam ser informados.

Recebido: Setembro 13, 2016 Aceito: Dezembro 05, 2016.

O estudo foi realizado na Universidade Federal da Bahia - UFBA, Clínica de Ruminantes e Equídeos, Santo Amaro, BA, Brasil.

\section{${ }^{*}$ Correspondência}

Tuanna Ranyelli Ramalho Fernandes Universidade Federal da Bahia - UFBA Av. Adhemar de Barros, 500, Ondina CEP 40170-110 - Salvador (BA), Brasil E-mail: tuannafernandes@hotmail.com

Copyright Fernandes et al. Este é um artigo publicado em acesso aberto (Open Access) sob a licença Creative Commons Attribution Non-Commercial, que permite uso, distribuição e reprodução em qualquer meio, sem restrições desde que sem fins comerciais e que o trabalho original seja corretamente citado. 
the left horn did not respond to treatment. A rotation of the same being observed. Physical examination showed a large mass $(16 \times 17 \times 8 \mathrm{~cm})$ with aspect of cauliflower, spongy consistency, irregular shape, fetid odor, with itching and bleeding easily. The same was located in cranioventral skin to the base of the horn and the left ear and deeply rooted inside the horn. After clinical evaluation complementary examinations were performed: blood count, radiographic examination and biopsy of the tumor mass. Blood count was observed the presence of severe anemia, hypoproteinemia and leukocytosis. Radiography showed occupation of the proximal and middle thirds of the left horn by tumor mass and prominences that surrounded the bones of the head. In histopathological evaluation was observed proliferation of atypical epithelial cells, moderately differentiated with nuclei rounded to ovoid, arranged in irregular cords and solid nests intermingled with sparse fibrous stroma presenting an infiltrative tumor manifest. Based on history, clinical signs, epidemiology and histological findings the diagnosis was closed in squamous cell carcinoma of the base of the horn. In such cases the main form of treatment is surgical resection of the tumor mass associated with dehorning. In this case due to the presence of advanced pregnancy, and poor clinical condition supportive treatment was shown to stabilize the patient until the delivery to be performed even after the surgery. After delivery, the animals showed a significant worsening of symptoms, with persistent recumbency, lack of appetite severe anemia, general weakness, showing no response to any treatment performed. After the owner's authorization was performed euthanasia and subsequent necropsy of the animal. In necropsy it was observed that the tumor emitted branches in the proximal portions and averages interior of horn and all left frontal sinus with lot of purulent fetid content and cellular debris. It was found in the caudal lobes of the lung nodules whitened of a tumor, tumor metastasis probable, and confirmed in the histopathological examination.

Keywords: tumor, bovine, horn, metastasis.

\section{Introdução}

Dentre as neoplasias que podem acometer os bovinos, a mais frequenteé o carcinoma de células escamosas (CCE), sobretudo, aqueles que se desenvolvem na região da vulva e dos olhos, sendo incomum na base do chifre. O CCE é um tumor maligno dos queratinócitos, conhecido também como carcinoma de células espinhosas, carcinoma espinocelular ou carcinoma epidermóide (Fernandes, 2001).

São neoplasias comuns em diversas espécies de animais domésticos, sua incidência aumenta com a idade, mas podem ocorrer em animais jovens (Fernandes, 2001; Goldschmidt \& Hendrick, 2002). Em bovinos, o CCE constitui uma doença importante, pois pode levar a perda na produção ou no valor zootécnico dos animais acometidos, além do óbito (Lemos \& Nakazato, 2001).

O CCE da base chifre, também conhecido como carcinoma do chifre, ou carcinoma do processo cornual é uma neoplasia maligna, localizada na transição da pele e estojo córneo, que invade a parte óssea do chifre e o seio frontal (Cotchin, 1956; Moulton,1961; Jubb \& Kennedy, 1970; Dirksen et al., 2005; Ginn et al., 2007). Em geral, possui baixa ocorrência, sendo observado mais frequentemente em animais velhos e, em cerca de, $2 \%$ dos animais do rebanho comercial, sobretudo, em raças de chifres longos e pelagem branca, na Índia, Indonésia, Sudão e Brasil (Dirksen et al., 2005; Lemos \& Nakazato, 2001). Naik et al. (1969) diagnosticaram o carcinoma do chifre em zebuínos das raças Khillari, Malvi, Kankrej, Gir, Nimari, Dangi e bovinos de raça indefinida, sendo as raças puras mais afetadas que nas mestiças. Lall (1953) descreveu a doença em zebuínos da raça Ilariana e também em búfalos Murrah. Balekundri (1935) encontrou a neoplasia em zebuínos da raça Amrit Mahal. Kulkarni (1953) e Naik \& Balakrishnan (1963) consideram a raça Kankrej como a mais susceptível. A neoplasia afeta, geralmente, apenas um dos chifres, sendo raros casos com comprometimento bilateral (Kulkarni, 1953).

A maioria dos casos de CCE da base do chifre é observada em animais entre cinco e dez anos de idade e tem baixa ocorrência em animais com menos de quatro anos de idade (Naik et al., 1969; Naik et al., 1970; Somvanshi, 1991). Bovinos machos castrados são mais acometidos do que vacas, enquanto que touros inteiros apresentam apenas ocasionalmente essa doença (Kulkarni, 1953; Naik et al., 1969; Fernandes, 2001).

Vários fatores predisponentes têm sido mencionados, dentre esses, destacam-se os fatores etiológicos intrínsecos, tais como predisposição genética e desequilíbrio hormonal, e fatores etiológicos extrínsecos, como trauma, produtos químicos, radiação solar, infestações parasitárias, vírus e irritação crônica por cordas (Ginn et al., 2007). Outro fator importante é a prática da apara, muito usada em algumas regiões indianas, que consiste na remoção parcial da camada externa 
córnea do chifre com a finalidade de melhorar sua forma (Balekundri, 1935; Kulkarni, 1953; Lall, 1953; Naik et al., 1969; Somvanshi, 1991).

Os sinais clínicos iniciais não são evidentes, entretanto, nos estágios avançados os animais são observados inquietos, inclinando a cabeça, com prurido e anormalidades morfológicas do chifre, além de secreção nasal do seio afetado e epífora (Kulkarni, 1947). Nos casos mais avançados há crescimento tumoral com aspecto de couve-flor na base do chifre, odor fétido e, normalmente, a lesão é complicada por miíases (Dirksen et al., 2005). O tratamento envolve a ressecção total do tecido tumoral evitando posteriormente ainda mais irritação, no entanto, o prognóstico é desfavorável (Lemos \& Nakazato, 2001; Dirksen et al., 2005).

O objetivo do presente trabalho é relatar um caso de carcinoma de células escamosas na base do chifre com metástase pulmonar em uma vaca da raça Gir com gestação avançada, atendida no Centro de Desenvolvimento da Pecuária(CDP) da UFBA.

\section{Histórico}

Em novembro de 2015, uma vaca, da raça Gir, com nove anos de idade, foi atendida no Centro de Desenvolvimento da Pecuária (CDP) da Universidade Federal da Bahia (UFBA), com histórico de rotação do chifre esquerdo após ferida profunda em sua base, sem resposta ao tratamento, seguido de rápido crescimento exofítico de uma massa de fácil sangramento, localizada na transição entre a pele e o chifre.

Ao exame físico, realizado no CDP-UFBA foi observado na pele crânioventral da base do chifree orelha esquerda uma grande massa tumoral (16x17x8cm), irregular, fétida, de consistência esponjosa e aspecto de couve-flor, pruriginosa e de fácil sangramento, que se infiltrava profundamente para o interior do corno esquerdo (Figura 1).

O animal apresentava descarga nasal serosa, intermitente, na narina esquerda, além de aumento do ruído laringotraqueal e traqueobrônquico, com som de passagem de líquido e discreto ronco inspiratório. Na palpação retal foi detectada gestação de, aproximadamente, seis a sete meses. Após avaliação clínica foram realizados exames complementares: hemograma, exame radiográfico e a biopsia da massa tumoral. O hemograma revelou anemia severa, hipoproteinemia e leucocitose. O exame radiográfico do chifre evidenciou invasão tumoral nos terços proximal e médio do corno esquerdo, além dos ossos adjacentes da base do chifre com possível infiltração do seio frontal (Figura 2).

Realizou-se exéreses cirúrgica das partes superficiais do tumor, com colheita de amostra para exames histopatológico, seguida de cauterização. A avaliação histopatológica da massa tumoral revelou proliferação de células epiteliais atípicas, moderadamente diferenciadas com núcleos

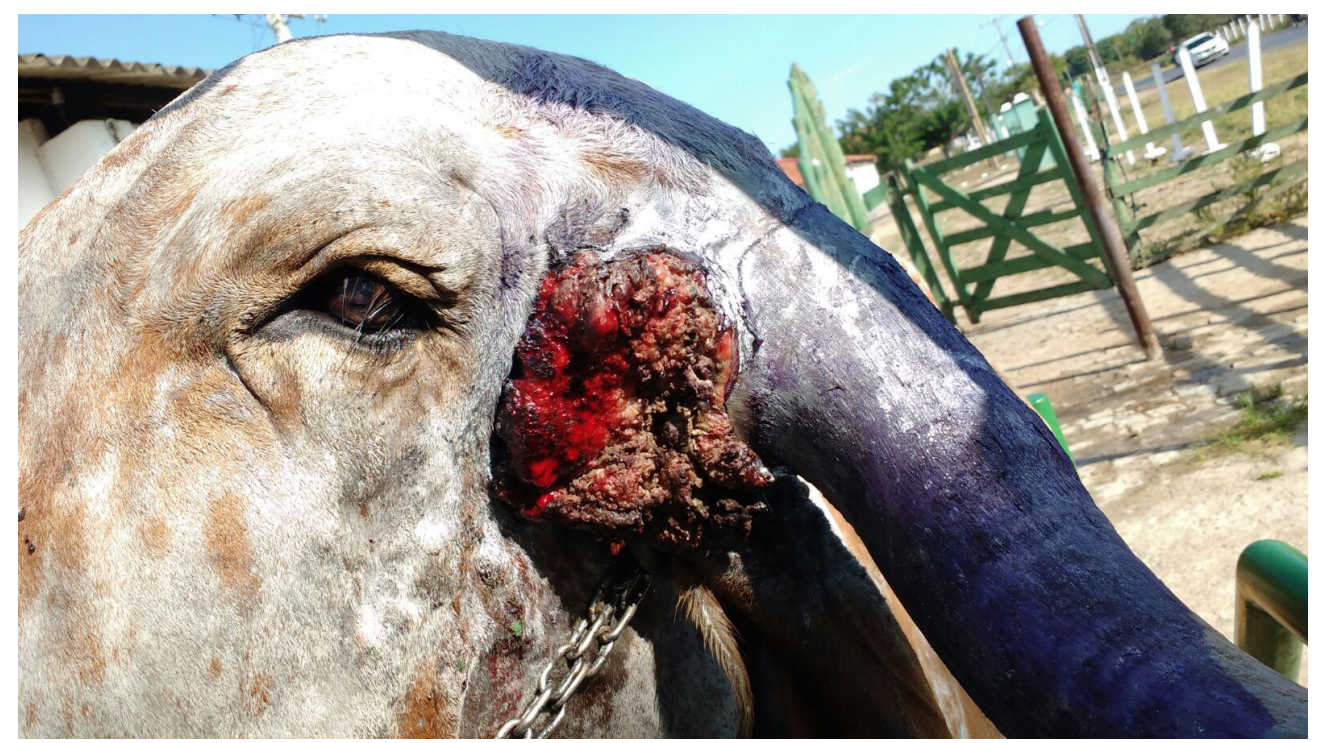

Figura 1. Aspecto macroscópico do carcinoma de células escamosas da base do chifre em vaca Gir adulta. 


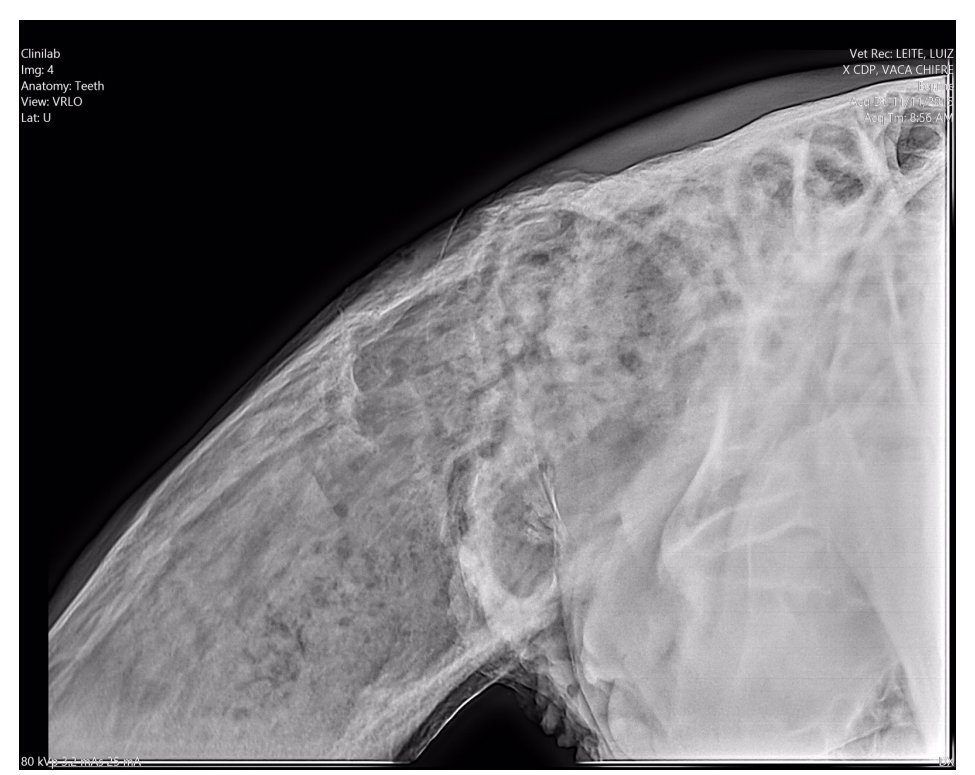

Figura 2. Radiografia do corno esquerdo evidenciando o seu preenchimento por massa tumoral.

arredondados a ovoides, levemente cromáticos, vesiculares, com nucléolos evidentes e volumoso citoplasma eosinofílico, arranjados em cordões irregulares e ninhos sólidos entremeados por escasso estroma fibroso. A neoplasia apresentava caráter infiltrativo manifesto. Adicionalmente, havia focos de necrose e hemorragia. Houve intenso infiltrado inflamatório neutrofílico, dezenas de colônias bacterianas intralesionais, focos de hemorragia e extensas áreas de necrose. Os achados microscópicos foram compatíveis com CCE da base do chifre (Figura 3).

Devido ao seu valor zootécnico, apesar do prognóstico desfavorável, o animal permaneceu internado, foi submetido a duas novas exéreses cirúrgicas, seguidas de cauterização das partes visíveis do tumor com intuído de controlar o crescimento tumoral e suas complicações (prurido, miíases e hemorragias), recebeu tratamento suporte e específico visando reverter à anemia e manter a gestação.

Cerca de dois meses depois, a vaca pariu um bezerro saudável. Devido à má condição da glândula mamária, o bezerro foi aleitado, desde o parto, com colostro e leite provenientes de outras vacas. Após o parto houve piora drástica do quadro clínico, com perda progressiva de peso, grave anemia e severa proliferação tumoral na base do chifre, evoluindo para decúbito persistente. Devido ao agravamento do quadro clínico o proprietário optou pela eutanásia. Imediatamente após a morte o animal foi necropsiado.

O examenecroscópico revelou massa neoplásica, medindo $18 \times 16 \times 5 \mathrm{~cm}$, com aspecto de couve-flor na base do chifre esquerdo, com evidente infiltração das porções proximais e médias do chifre acometido, bem como de todo o seio frontal esquerdo, associada a intenso exsudato purulento fétido e detritos celulares preenchendo a porção final do chifre, além de múltiplos nódulos com até 3,0cm de diâmetro nos lobos caudais dos pulmões com características morfológicas semelhantes ao tumor da base de chifre. Adicionalmente, havia uma massa amarelada, de consistência firme na região mediastínica próxima ao coração, sinusite supurativa moderada, anemia, caquexia, linfadenomegalia moderada dos pré-escapulares e parotídeo esquerdo, moderada hepatomegalia e mastite crônica.

Durante a necropsia foram colhidos fragmentos da massa tumoral, pulmão, coração e linfonodo mediastínico. Esse material foi fixado em formol a 10\% tamponado e processado pela técnica rotineira de inclusão em parafina e corado com hemotoxilina e eosina no Laboratório de Patologia Veterinária (LPV) da UFBA.

A avaliação microscópica dos fragmentos da massa da base do chifre confirmou o resultado da biópsia prévia e revelou ainda, em meio ao parênquima pulmonar, metástase de CCE primário da base do chifre (Figura 4); já a massa próxima ao coração tratava-se de um abscesso e nos linfonodos havia marcada hiperplasia reacional. 


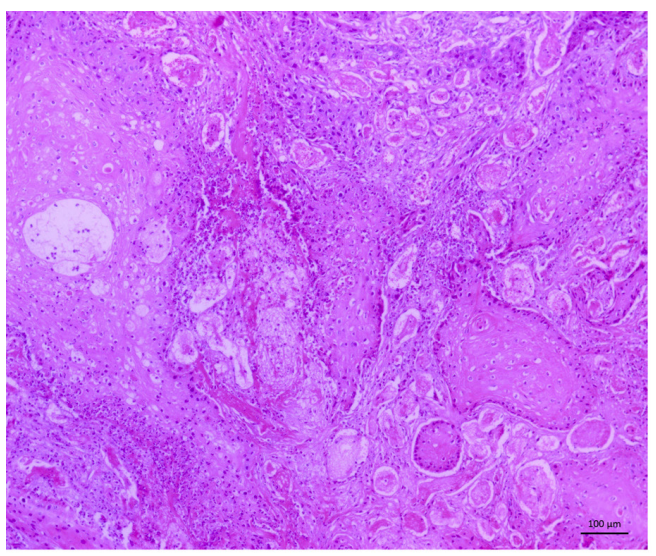

(a)

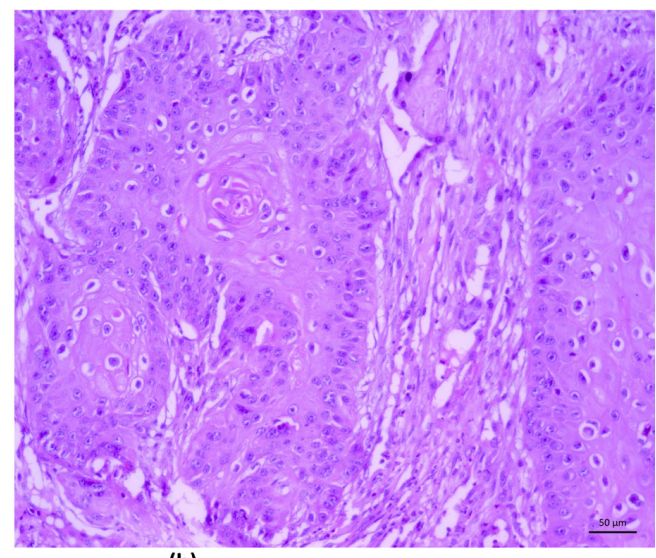

(b)

Figura 3. (a) Fotomicrografia do carcinoma de células escamosas da base do chifre em um bovino. Marcada proliferação neoplásica de células escamosas atípicas, arranjadas em cordões e ninhos sólidos entremeados por escasso estroma fibroso. Notar o carácter infiltrativo, bem como focos de necrose e intenso infiltrado inflamatório neutrofílico. HE, Obj. 10x; (b) Fotomicrografia do carcinoma de células escamosas da base do chifre em um bovino. Proliferação de células epiteliais atípicas, moderadamente diferenciadas com núcleos arredondados a ovoides, levemente cromáticos, com nucléolos evidentes e volumoso citoplasma eosinofílico, arranjados em cordões irregulares e ninhos sólidos. Notar pequenos focos de diferenciação escamosa. HE, Obj. 20x.

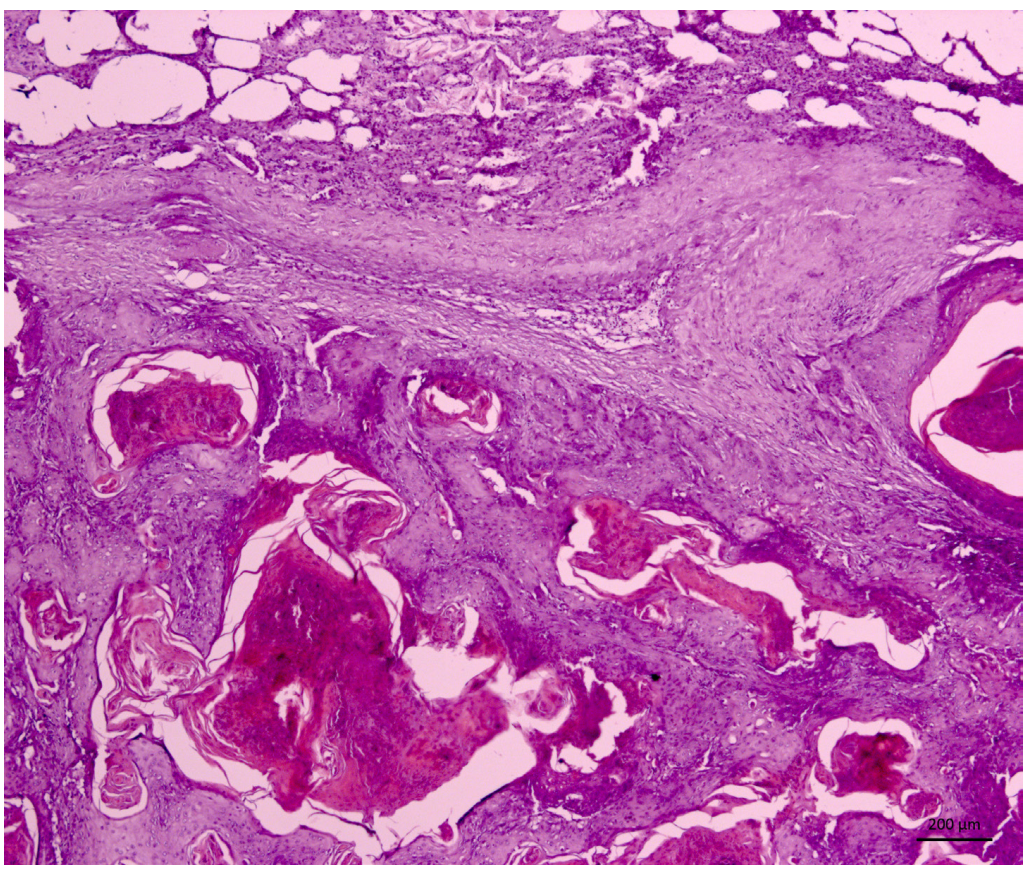

Figura 4. Fotomicrografia da metástase pulmonar do carcinoma de células escamosas da base do chifre em um bovino. Notar a marcada proliferação neoplásica sólida, sob a forma de ninhos e trabéculas, com grandes áreas de diferenciação escamosa e formações de "pérolas córneas" em meio ao parênquima pulmonar. HE, Obj. 5x.

\section{Discussão}

O diagnóstico de CCE da base do chifre com metástase pulmonar foi baseado nos achados clinico-epidemiológicos, radiográficos, necroscópicos e confirmado pela histopatologia. Dentre as várias causas de CCE da base do chifre apontadas na literatura, destacam-se a predisposição genética incluindo raça, idade e sexo, trauma, radiação solar e irritação crônica por cordas (Kulkarni, 1953; Lall,1953; Naik et al., 1969). Os achados clínicos relatados por Kulkarni (1947) e Lemos \& Nakazato (2001) como inquietação ("sacudidas de cabeça"), prurido (tendência a coçar a base do chifre com 
o membro posterior e contra objetos), secreção nasal, inclinação da cabeça, anormalidades do chifre com marcado aumento de diâmetro de sua base, gradual amolecimento, posição anormal e ulcerações foram semelhantes aos descritos no presente relato. De acordo com Dirksen et al. (2005), nos casos mais avançados há marcada proliferação neoplásica altamente vascularizada e friável, com aspecto de couve-flor na base do chifre e odor fétido e segundo Pulley \& Stannard (1990) e Lemos \& Nakazato (2001), animais cronicamente afetados podem demonstrar emagrecimento progressivo e anemia, podendo chegar ao óbito. Todos estes fatos foram igualmente observados no animal em questão.

Essa neoplasia tem sido relatada, principalmente, na Índia com prevalência de 1\% no rebanho bovino (Naik et al., 1969, 1970), mas também é descrita na Sumatra (Burggraaf, 1935), Iraque (Zubaidy, 1976) e Brasil (Lemos, 1998). Acredita-se que a ocorrência dessa neoplasia no Brasil seja pouco frequente ou subnotificada devido ao sistema de produção, no qual a maioria dos animais são abatidos em idade precoce, reduzindo assim a incidência de neoplasias. No presente trabalho, devido ao fato de tratar-se de vaca doadora de embriões, já possuía idade avançada, o que favoreceu o desenvolvimento do tumor. Ainda em relação aos dados epidemiológicos, cabe ressaltar que o uso constante de cabresto na vaca, causava constante atrito da corda no local onde a neoplasia teve origem. Segundo descrito na literatura, uma das principais causas de CCE da base do chifre se refere ao uso de cordas e técnicas de apara dos chifres que resultam comumente em traumatismos repetitivos na base do chifre (Singh \& Batra, 2005). Segundo Singh (1986), a aparência radiográfica varia de acordo com o grau de envolvimento, sendo o núcleo do chifre preenchido por uma massa de tecido mole homogênea, proliferação periosteal ou esclerose ao redor das margens do chifre. As características radiográficas relatadas no presente caso são semelhantes às descritas na literatura. Os achados histopatológicos ora relatados foram semelhantes aos descritos na literatura por outros autores (Naik et al., 1969). Segundo Kulkarni (1953), embora raro, o CCE pode cursar com metastatização para pulmão, fígado e linfonodos. No presente caso, verificou-se metástase pulmonar, sem envolvimento de outros órgãos, o que pôde ser confirmado pela histopatologia, descartando a possível metástase para linfonodos mediastínicos sugerida durante a necropsia, mas que de fato, tratava-se de processo necrótico abscedativo. Convém ressaltar que, embora seja indicada na literatura a remoção cirúrgica total do tecido tumoral e a descorna, o procedimento não foi possível devido ao estado de prenhez, grave anemia, tamanho e agressividade do tumor, sendo adotados apenas métodos paliativos visando levar a gestação a termo.

Em relação a "doenças" que supostamente acometem os chifres cabem algumas considerações. Cabe ressaltar que historicamente, Tokarnia et al. (1959) estudaram o chamado "mal dos chifres", tido como doença que acometeria o gado, sobretudo, no nordeste e norte do Brasil. Naquela ocasião, a suposta etiologia era bastante divergente pelos criadores e vaqueiros, sendo a causa mais comumente difundida uma deficiência mineral, que causava importantes perdas econômicas. As lesões atribuídas ao "mal dos chifres" incluíam chifres ôcos, quentes repletos de pus e que exibiam hemorragia ou não ao serem perfurados, bem como corrimento nasal, epífora e, por vezes, amolecimento dos dentes. Tokarnia et al. (1959) então colheram informações o "mal dos chifres" e examinaram 52 bovinos tidos como enfermos e concluíram que o "mal dos chifres" é um "diagnóstico" dado a diversos estados patológicos, ou tido como patológicos, ou seja, o termo não designa uma doença ou certo grupo de doenças, mas sim é empregado para explicar sinais clínicos e lesões, por vezes imaginárias em bovinos. Tal estudo foi fundamental para elucidação desse equívoco que ocorria naquela época, de fato, hoje não encontramos mais menção no campo dessa "doença", em nossa área de atuação, no estado da Bahia, nordeste do Brasil.

\section{Conclusão}

O presente artigo relata um caso infrequente de CCE de base do chifre com metástase pulmonar, o que demonstra que além da grande capacidade de invasão e destruição local, o quadro clínico resultante dessa neoplasia pode ser agravado pelo comprometimento de órgãos vitais à distância, sendo um agravante ao tratamento e tornando o prognóstico desfavorável. 


\section{Referências}

Balekundri, G. S. (1935). A brief note on epithelial tumours occurring at tail base of bons vi Amrit Mabalbuilocks. The Indian Veterinary Journal, 11(4), 279-280.

Burggraaf, H. (1935). Kankera an de basis van de horns bij zebus: horn disease of cattle. Tijdschrift voor Diergeneeskunde, 62, 1121-1136.

Cotchin, E. (1956). Neoplasms of the domeaticated mammals (Review Series, No. 4, pp. 3). England: Commonw. Bur. Anim. Hit. Conmonwealth Agricultural Bureaux, Farbam Royal.

Dirksen, G., Grunder, H. D., \& Stober, M. (2005). Medicina Interna y cirugía del bovino (4th ed., Vol. 1). Buenos Aires: Inter-Médica.

Fernandes, C. G. (2001), Neoplasias em ruminantes e equinos. In F. Riet-Correa, A. L. Schild, R. A. A. Lemos \& Borges J. R. J. (Eds.), Doenças de ruminantes e eqüinos (2. ed., Vol. 2, pp. 538-544). Santa Maria: Pallotti.

Ginn, P. E., Mensett, J. E. K. L., \& Rukich, P. M. (2007). Skin and appendages. In M. Maxie (Eds.), Jubb, Kennedy \& Palmer's: pathology of domestic animals (5th ed., Vol. 1, pp. 553-781). Philadelphia: Saunders/Elsevier.

Goldschmidt, M. H., \& Hendrick, M. J. (2002). Tumors of the skin and soft tissues. In D. J. Meuten (Eds.), Tumors in domestic animals (4th ed., pp. 45-118). Iowa: Iowa State Press.

Jubb, K. V. F., \& Kennedy, P. C. (1970). Pathology of domestic animals (2nd ed., Vol. 2, p. 645). New York: Academic Press.

Kulkarni, H. V.(1947). Carcinoma of the horn in bovines. The Indian Veterinary Journal, 23(5), 370-373. PMid:20295905.

Kulkarni, H. V. (1953). Carcinoma of the horn lo bovines of the Old Baroda State. The Indian Veterinary Journal, 29(5), 415-421.

Lall, H. K. (1953). Incidence of Horn Cancer in Meerut Circle, Uttar Pradesh. The Indian Veterinary Journal, 30, 205-209.

Lemos, R. A. A., Nakazato, L., \& Barros, C. S. L. (1998). Carcinoma da base do chifre. In: R. A. A. Lemos (Eds.). Principais enfermidades de bovinos de corte do Mato Grosso do Sul (pp.497-498). Universidade Federal do Mato grosso do Sul: Campo Grande.

Lemos, R. A. A., \& Nakazato, L. (2001). Carcinoma de base de chifre. In F. Riet-Correa, A. L. Schild, R. A. A. Lemos \& Borges J. R. J. (Eds.), Doenças de ruminantes e eqüinos (2. ed., Vol. 2, pp. 544-546). Santa Maria: Pallotti.

Moulton, J. E. (1961). Tumors in domestic animal (p. 44). Berkeley: University California Press.

Naik, S. N., \& Balakrishnan, V. (1963). Item cancer in bovines of We tem India. The Indian Veterinary Journal, 40, 216-221.

Naik, S. N., Balakrishnan, C. R., \& Randelia, H. P. (1969). Epidemiology of Horn Cancer in Indian Zebu Cattle: Breed incidence. The British Veterinary Journal, 125(5), 222-230. http://dx.doi.org/10.1016/S0007-1935(17)48959-7.

Naik, S. N., Randelia, H. P., \& Dabholkar, R. D. (1970). Carcinoma of the horn in a cryptorchidbull. Pathologia veterinaria, 7(3), 265-269. http://dx.doi.org/10.1177/030098587000700304 PMid:5534258.

Pulley, L. T., \& Stannard, A. P. (1990). Tumors of the skin and soft tissues. In J. E. Moulton (Ed.), Tumors in domestic animals (3. ed., pp. 16-74). Davis: California University Press.

Singh, G. K., \& Batra, M. (2005). Important aspects of horn câncer. Nagar: College of Veterinary and Animal Sciences, Pant University of Agriculture and Technology.

Singh, G. R., Somvanshi, R., \& Bhargava, A. K. (1986). Radiographic diagnosis of bovine horn cancer (Squamous cell carcinoma). Veterinary Radiology, 27(6), 180-181. http://dx.doi.org/10.1111/j.1740-8261.1986.tb00031.x.

Somvanshi, R. (1991). Horn cancer in Indian cattle. The Veterinary Bulletin, 61(9), 901-911.

Tokarnia, C. H., Döbereiner, J., \& Canella, C. F. C. (1959). Estudo sobre o "mal dos chifres" em gado do Nordeste e Norte do Brasil. Arquivos do Instituto Biológico Animal, (2), 39-64.

Zubaidy, A. J. (1976). Horn câncer in cattle in Iraq. Veterinary Pathology, 13(6), 453-454. http://dx.doi. org/10.1177/030098587601300608. PMid:1006957. 